\title{
Activation of Adenylyl Cyclase Causes Stimulation of Adenosine Receptors
}

\author{
Thomas Plelia Antonia Mondorfa Nerea Ferreiros ${ }^{b} \quad$ Dominique Thomas $^{b}$ \\ Karel Dvorak $^{\mathrm{a}}$ Ricardo M. Biondia ${ }^{\mathrm{a}}$ Dagmar Meyer zu Heringdorf ${ }^{c}$ \\ Stefan Zeuzem ${ }^{\mathrm{a}} \quad$ Gerd Geisslinger $^{\mathrm{b}} \quad$ Herbert Zimmermann ${ }^{\mathrm{d}}$ Oliver Waidmann ${ }^{\mathrm{a}}$ \\ Albrecht Piipera \\ ${ }^{a}$ Department of Medicine 1, Goethe-University Hospital Frankfurt, Frankfurt, ${ }^{b}$ Pharmazentrum \\ Fankfurt/ZAFES, Institute of Clinical Pharmacology, Goethe-University Hospital Frankfurt, Frankfurt, \\ cpharmazentrum frankfurt/ZAFES, Institute of Pharmacology, Goethe-University Hospital Frankfurt, \\ Institute of Cell Biology and Neuroscience, Goethe-University, Frankfurt, Germany
}

\section{Key Words}

adenosine receptors $\bullet$ cAMP • Adenylyl cyclase $\bullet$ eNPP2 $\bullet$ MRP4 $\bullet$ PKA

\begin{abstract}
Background/Aims: Signaling of $\mathrm{G}_{\mathrm{s}}$ protein-coupled receptors (GsPCRs) is accomplished by stimulation of adenylyl cyclase, causing an increase of the intracellular cAMP concentration, activation of the intracellular cAMP effectors protein kinase A (PKA) and Epac, and an efflux of CAMP, the function of which is still unclear. Methods: Activation of adenylyl cyclase by GsPCR agonists or cholera toxin was monitored by measurement of the intracellular CAMP concentration by ELISA, anti-phospho-PKA substrate motif phosphorylation by immunoblotting, and an Epac-FRET assay in the presence and absence of adenosine receptor antagonists or ecto-nucleotide phosphodiesterase/pyrophosphatase2 (eNPP2) inhibitors. The production of AMP from CAMP by recombinant eNPP2 was measured by HPLC. Extracellular adenosine was determined by LC-MS/MS, extracellular ATP by luciferase and LC-MS/MS. The expression of eNPP isoenzymes 1-3 was examined by RT-PCR. The expression of multidrug resistance protein 4 was suppressed by siRNA. Results: Here we show that the activation of GsPCRs and the GsPCRs-independent activation of $\mathrm{G}_{s}$ proteins and adenylyl cyclase by cholera toxin induce stimulation of cell surface adenosine receptors $\left(A_{2 A}\right.$ or $A_{2 B}$ adenosine receptors). In PC12 cells stimulation of adenylyl cyclase by GsPCR or cholera toxin caused activation of $A_{2 A}$ adenosine receptors by an autocrine signaling pathway involving CAMP efflux through multidrug resistance protein 4 and hydrolysis of released CAMP to AMP by eNPP2. In contrast, in PC3 cells cholera toxin- and GsPCR-induced stimulation of adenylyl cyclase resulted in the activation of $A_{2 B}$ adenosine receptors. Conclusion: Our findings show that stimulation of adenylyl cyclase causes a remarkable activation of cell surface adenosine receptors.
\end{abstract}




\section{Introduction}

Numerous hormones and neurotransmitters mediate their effects on target cells by binding to $G$ protein-coupled receptors that either stimulate (GsPCR) or inhibit ( $G_{i}$ proteincoupled receptors) the activity of adenylyl cyclase that catalyzes the formation of cAMP from ATP. Alterations of the intracellular cAMP concentration ([cAMP $]_{\mathrm{i}}$ ) regulate a large number of cellular processes, affecting e.g. the control of various metabolic events, in particular glucose metabolism, muscle contraction, secretion, memory, and immune function [1-3]. cAMP binds to and activates intracellular cAMP effectors, i. e. protein kinase A (PKA), cAMPdependent Rap-exchange factors (Epacs) and cAMP-gated ion channels [2-4]. A-kinase anchoring proteins (AKAPs) target PKA to specific substrates and distinct subcellular compartments, providing spatial and temporal specificity for mediation of biological effects channeled through the cAMP/PKA pathway [5]. Stimulation of adenylyl cyclase also leads to an efflux of cellular cAMP through multidrug resistance protein 4 (MRP4), which may serve to regulate $[\mathrm{CAMP}]_{\mathrm{i}}$ signaling following activation of adenylyl cyclase [6-9]. No receptor for extracellular cAMP has been found on mammalian cells. Whether extruded cAMP itself serves as an extracellular signaling molecule in its own right or precursor of an extracellular signaling molecule in mammalian cells is not entirely clear.

P1 purinergic receptors (adenosine receptors) are activated by adenosine and AMP and are important regulators of adenylyl cyclase. Whereas $A_{2 A}$ and $A_{2 B}$ adenosine receptors couple to $G$ proteins $\left(G_{s}\right)$,which stimulate adenylyl cyclase and thereby increase the levels of intracellular cAMP, $A_{1}$ and $A_{3}$ receptors inhibit adenylyl cyclase activity via $G_{i}$ proteins $[10,11]$. A well-established mode of activation of adenosine receptors occurs under stress conditions such as hypoxia and inflammation and upon stimulation of some $\mathrm{G}$ protein-coupled receptors which induce mobilization of intracellular calcium. This involves the release of cellular ATP, which causes activation of P2 purinergic receptors and - after hydrolysis to AMP by CD39 (ectonucleoside triphosphate diphosphohydrolase 1) and further to adenosine by ecto-5'nucleotidases (CD73) or ecto-alkaline phosphatases - of P1 (adenosine) receptors [10-13]. In the brain translocation of adenosine via equilibrative nucleoside transporters (ENTs) represents an additional source of extracellular adenosine [14-17].

Here we investigated if activation of adenylyl cyclase by GsPCRs or cholera toxin (CTx), which directly activates $G_{s}$ proteins and is thus considered to stimulate adenylyl cyclase independently of GsPCRs, represents an alternative pathway for modulating the release of adenine nucleotides and regulating purinergic signaling. Our data show that activation of adenylyl cyclase causes an elevation in the concentration of extracellular adenosine and activation of $G_{s}$ protein-coupled adenosine receptors $\left(A_{2 A}\right.$ and $A_{2 B}$ adenosine receptors).

\section{Materials and Methods}

\section{Cell culture and stimulation}

Neuroendocrine PC12 (American Type Culture Collection) and PC3 prostate carcinoma cells (European Collection of Authenticated Cell Cultures) were grown in DMEM containing 5\% horse serum and $5 \%$ fetal calf serum supplemented with antibiotics [18]. Cells were serum-starved for $4 \mathrm{~h}$ prior to their exposure to stimuli (CTx, adenosine, AMP and CGS 21680, LPA, isoproterenol, glucagon (all from SigmaAldrich), or PACAP (PACAP38, Calbiochem)), in serum-free DMEM in the presence or absence of inhibitors (ZM 241385 (Tocris), SCH 58261, MRS 1754, S32826, ARL67156, 4-nitrobenzylthioinosine (NBMPR) (all from Sigma-Aldrich) or HA155 (Merck Millipore)).

\section{Suppression of MRP4 expression by siRNA}

Control siRNA (AACUGGGUAAGCGGGCGCAtt) or siRNA directed against MRP4 (CCGAGUAGUUCAGCCCAUAtt, $50 \mathrm{nM}$ ) were transfected into PC12 cells using the Lipofectamine RNAiMAX reagent in OptiMEM using as described by the manufacturer (Thermo Fisher Scientific). On the next day the medium was replaced by complete cell culture medium. The cells were used for the experiments $72 \mathrm{~h}$ after transfection. Down-modulation of MRP4 expression was monitored by immunoblotting. 


\section{Cellular Physiology Cell Physiol Biochem 2018;45:2516-2528

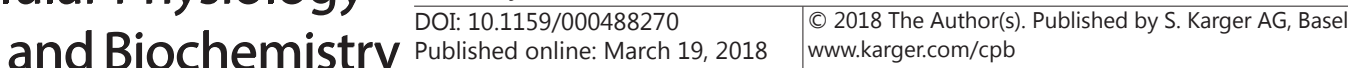

\section{Immunoblotting}

Immunoblotting of cellular lysates was performed as recently described $[18,19]$. For the detection of ecto-nucleotide phosphodiesterase/pyrophosphatase 2 (eNPP2) in the cell culture media the cells grown on six well plates were washed and switched to OptiMEM. After $24 \mathrm{~h}$ the supernatants were collected and centrifuged ( $5 \mathrm{~min}, 500 \mathrm{~g}$ ) to remove cell debris. The supernatants were concentrated 10-20-fold using Amicon columns with cut-off of $50 \mathrm{kDa}$ (Millipore).

The blots were probed with antibodies against PKA substrate motif [RXXp(S/T)] (Cell Signalling), MRP4 (Abcam), eNPP2 (GeneTex), Extracellular signal-regulated kinase (ERK) 2 (Santa Cruz Biotechnology) or $\beta$-actin (Sigma-Aldrich). Antigen-antibody complexes were visualized using horseradish peroxidaseconjugated antibodies (BioRad) and the enhanced chemiluminescence system (Pierce) using a Fuji LAS 4000 camera system or by fluorescently labelled secondary antibodies (Leica) using a FLA-9000 image scanner and the software MultiGauge version 3.0 (FujiFilm).

RT-PCR

Total RNA was isolated from PC12 cells with TRIZOL reagent (Sigma-Aldrich) according to the manufacturer's instructions. cDNA was generated from $1 \mu \mathrm{g}$ RNA using M-MLV RT polymerase (Promega) and random primer hexamers (Thermo Fisher Scientific). The reaction was run for $1 \mathrm{~h}$ at $37^{\circ} \mathrm{C}$. Two $\mu \mathrm{l}$ of the cDNA were used for the PCR reaction using DreamTaq Polymerase (Thermo Fisher Scientific) for amplification of target genes. RNA from rat tissue was used as positive control. The samples were analyzed by DNA gel electrophoresis and staining with ethidium bromide. For the verification the bands were isolated and cloned in the pGEM-T vector (Promega). The identities of the inserts were verified by sequencing on an GeneAMP® PCR System 9700 (Applied Biosystems).

The following primers were used: eNPP1-for (GAATTCTTGAGTGGCTACAGCTTCCTA), eNPP1rev (CTCTAGAAATGCTGGGTTTGGCTCCCGGCA), eNPP2-for (CGCTCGAGGCTTTCCAAGAATCCCTC), eNPP2-rev (CTCTAGACTACACTGCCCAGGCCCA), eNPP3-for (AGCCGCCGGTTATCTTGTTCTC), eNPP3-rev (TGATGCCGTGCGACTCTGGATAC) [20].

FRET assay

cAMP sensor, termed ${ }^{\mathrm{T}} \mathrm{Epac}^{\mathrm{VV}}$, which employs mTurquoise as donor and Venus Venus as acceptor protein was used in the present study [21]. PC12 cells were seeded on 6-well plates coated with Collagen G (Biochrom) and transfected with the plasmid using Lipofectamine LTX (Thermo Fisher Scientific). After 24 $\mathrm{h}$ the cells were seeded on collagen $\mathrm{G}$ coated 8-well slides (IBIDI).

Experiments were performed in HEPES-buffered saline (Sigma-Aldrich) at $37^{\circ} \mathrm{C}$ in a $5 \% \mathrm{CO}_{2}$ atmosphere. Images were taken using a Zeiss 510 confocal microscope (Zeiss) using a 40x, 1.3 N.A. glycerol immersion objective. Donor excitation was with the $442 \mathrm{~nm}$ HeCd laser; donor emission was collected between 450 and $505 \mathrm{~nm}$ and acceptor emission between 510 and $600 \mathrm{~nm}$ by setting the SP 5 spectrometer accordingly. Pictures were taken every 20 seconds over 60 minutes. Pulse duration and the scanning time was 1 second. Agonists and inhibitors were added $90 \mathrm{sec}$ after starting the procedure and generation of the baseline from concentrated stocks. Data from 6-15 cells per experiment are presented as mean \pm SD.

cAMP assay

cAMP was extracted from the cells with $0.1 \mathrm{M} \mathrm{HCl}$. To determine $[\mathrm{cAMP}]_{\mathrm{e}}$, the medium was mixed with an equal volume of $0.2 \mathrm{M} \mathrm{HCl}$. The subsequent steps for the determination of cAMP were performed by enzyme immuno assay (Cayman Chemicals) as described [18].

ATP assay

Extracellular ATP was determined by a Luciferase-based assay as described by the manufacturer (Thermo Fisher Scientific) using an EnVision apparatus (Perkin Elmer).

Measurement of the degradation of CAMP by recombinant eNPP2 by HPLC analysis

Human recombinant eNPP2 (2 $\mu \mathrm{g}$ ) (R\&D Systems) was incubated with $2 \mathrm{mM} \mathrm{N}{ }^{6}$-etheno-cAMP ( $\varepsilon$-cAMP) (Biolog) in a buffer containing $10 \mathrm{mM} \mathrm{CaCl}_{2}, 5 \mathrm{mM} \mathrm{MgCl}_{2}, 0.02 \%$ Brij-35 (v/v), $50 \mathrm{mM}$ Tris pH 8.5. Where indicated the autotaxin inhibitor $\mathrm{S} 32826(100 \mu \mathrm{M})$ was added. The enzymatic reaction was run at $37^{\circ} \mathrm{C}$ in the Agilent auto-sampler. At the beginning every 15 minutes an aliquot was automatically taken and analyzed by an Agilent HPLC 1200 system with a fluorescence detector (Agilent Technologies). The fluorescence from etheno-derivated adenosine and nucleotides was measured at $\lambda \mathrm{ex}=280 \mathrm{~nm}$ and $\lambda \mathrm{em}=410 \mathrm{~nm}$ as previously 


\section{Cellular Physiology Cell Physiol Biochem 2018;45:2516-2528

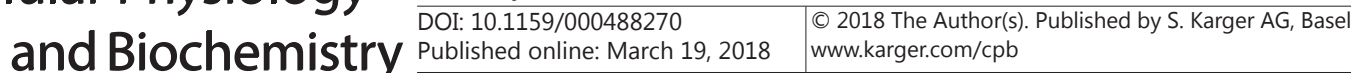 \\ Pleli et al.: Adenosine Receptors in Adenylyl Cyclase Signaling}

described [22]. Compound separation was carried out on an Agilent Zorbax XDB-C18 (4.6 x 50 mm; 1.5$\mu \mathrm{m})$ column with an upstream connected analytical guard column ( 4.6 x $12.5 \mathrm{~mm}$; 5 - $\mu \mathrm{m}$ (Agilent). Ten- $\mu \mathrm{l}$ samples were injected by an autosampler and adenine nucleotide/nucleoside analogues were eluted with a flow rate of $0.75 \mathrm{ml} / \mathrm{min}$ using a gradient of buffer $\mathrm{A}\left(30.5 \mathrm{mM} \mathrm{KH}_{2} \mathrm{PO}_{4}, 5.7 \mathrm{mM}\right.$ tetrabutylammonium hydrogen sulfate (TBAS), pH 5.8,6\% acetonitril) and buffer B (30.5 mM KH $\mathrm{PO}_{4}, 5.7 \mathrm{mM}$ TBAS, pH 5.8, $65 \%$ acetonitrile). Initial conditions were $100 \%$ eluent A that linearly decreased to $66 \%$ within 5.6 min. This condition was maintained for $2.4 \mathrm{~min}$, followed by washing the column with $70 \%$ of buffer B for one min and equilibration with $100 \%$ buffer A for 4.5 min prior to the next run. External standards of known concentrations were used to determine retention times and to permit sample quantification based on the analysis of peak area. ChemStation Software (Agilent) was used for report and analysis of the data.

\section{Determination of adenosine and ATP by LC-MS/MS}

The concentrations of ATP, adenosine and cAMP in the samples were analyzed by liquid chromatographyelectrospray ionization-tandem mass spectrometry as previously described [23]. Briefly, the analytes were extracted from $50 \mu \mathrm{l}$ cell culture supernatant by protein precipitation with methanol and the supernatant was divided in two fractions. One fraction was used for the quantification of ATP, the other one for the analysis of adenosine and cAMP. For the chromatographic analysis of the ATP, an anion exchange HPLC column (BioBasic AX, $150 \times 2.1 \mathrm{~mm}$, Thermo) and a 5500 QTrap (Sciex) were used as analyzers, operating as triple quadrupole in positive multiple reaction monitoring (MRM) mode. The analysis of ATP was performed as previously described [23]. Adenosine and cAMP were analyzed using an Atlantis T3 column (100 x 2.1 $\mathrm{mm}$, Waters). Adenosine was analyzed similarly as described previously [23], cAMP was quantified using ${ }^{13} \mathrm{C}_{5}$-cAMP as internal standard. The precursor-to-product ion transitions used as quantifier for cAMP was $\mathrm{m} / \mathrm{z} 328.0 \rightarrow$ 134.0. Calibration ranges were 5-1, $000 \mathrm{ng} / \mathrm{ml}$ for ATP, $1.25-250 \mathrm{ng} / \mathrm{ml}$ for adenosine and $0.5-100 \mathrm{ng} / \mathrm{ml}$ for cAMP.

\section{Statistical Analysis}

All experiments were performed at least three times independently. Quantitative data are expressed as mean \pm standard deviation. Statistical analysis was performed by paired or unpaired Student $t$ tests using the BiAS software for Windows (version 9.11, Epsilon-Verlag). $P$ values of $<0.05$ were considered statistically significant.

\section{Results}

Extracellular adenosine and $A_{2}$ adenosine receptors are involved in GsPCR as well as in cholera toxin (CTX)-induced activation of adenylyl cyclase in PC12 and PC3 cells

Using neuroendocrine PC12 cells as a model system, we initially studied the role of extracellular adenosine and adenosine receptors in the activation of adenylyl cyclase by pituitary adenylyl cyclase-activating peptide (PACAP) and by CTx, which directly stimulates $\mathrm{G}_{\mathrm{s}}$ proteins and thus bypasses receptor activation. In these cells, $A_{2 A}$ adenosine receptors $\left(A_{2 A} R s\right)$ are the only functionally relevant adenosine receptors [24]. As expected, adenosine caused an increase in the phosphorylation of PKA substrate motifs, a convenient method to determine PKA activation in situ. This was completely blocked by the addition of adenosine deaminase (ADA, $1 \mathrm{U} / \mathrm{ml}$ ) (for all online suppl. material, see www.karger.com/ doi/ 10.1159/000488270, Fig. S1A and S1B), which scavenges extracellular adenosine, or by the $A_{2 A} R$ adenosine receptor $\left(A_{2 A} R\right)$ antagonists ZM $241385(10 \mu M)$ and SCH $58261(100$ $\mathrm{nM}$ ) (see online suppl. material, Fig. S1A and S1C). Remarkably, $A_{2 A} R$ blockers and ADA also reduced the increase in $[\mathrm{CAMP}]_{\mathrm{i}}$ and in PKA substrate motif phosphorylation in response to PACAP (Fig. 1A and 1B) and CTx (200 U/ml) (Fig. 1C-F, (see online suppl. material) Fig. S1D and S1E). In general, the effects of ADA were smaller than those of $A_{2 A} R$ blockers (compare Fig. 1D with 1F).

To obtain direct, time-resolved, non-disruptive information on the role of extracellular adenosine on the CTx-induced increase in [CAMP $]_{i}$ and activation of PKA in PC12 cells, we used

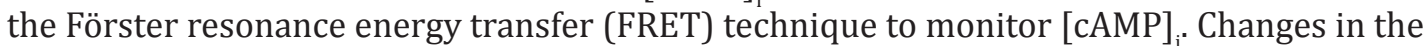
FRET signal were monitored by confocal laser scanning fluorescence microscopy [cAMP] ${ }_{\mathrm{i}}$ 
Fig. 1. $A D A$ and $A_{2 A} R$ antagonists inhibit GsPCR- or CTx-induced increase in $[\mathrm{CAMP}]_{\mathrm{i}}$ and PKA substrate motif phosphorylation in PC12 cells. (A) Effect of ADA on PACAP-induced adenylyl cyclase activation. Serum-starved PC12 cells were pre-incubated with ADA (1 $\mathrm{U} / \mathrm{ml}$ ) for $5 \mathrm{~min}$, followed by stimulation with $100 \mathrm{nM}$ PACAP or vehicle for the indicated time. The amount of cellassociated cAMP reflecting [cAMP] $]_{i}$ was determined by enzyme immunoassay $(n=4)$. (B) Effect of ADA on PACAP-induced PKA substrate motif phosphorylation. Serum-starved PC12 cells were pre-incubated with ADA $(1 \mathrm{U} / \mathrm{ml})$ for 5 min, followed by stimulation with the indicated concentration of PACAP or vehicle for $10 \mathrm{~min}$. The amount of PKA substrate motif phosphorylation was determined by immunoblotting with anti-PKA substrate motif phosphorylation. Protein loading of the lanes was controlled by anti-ERK2 immunoblotting ( $n=3)$. (C) Effect of ADA and SCH 58261 on CTx-induced [cAMP]. Serum-starved cells were pre-incubated with ADA ( $1 \mathrm{U} / \mathrm{ml}$ ) or vehicle for $15 \mathrm{~min}$, followed by stimulation with CTx (200 U/ml) for the indicated time. The amount of intracellular cAMP in the cells was determined as described in (A) (n=3). (D) Effect of ADA on CTx-induced PKA substrate motif phosphorylation. Serum-starved cells were pre-incubated with ADA $(1 \mathrm{U} / \mathrm{ml})$ or vehicle for $15 \mathrm{~min}$, followed by stimulation with CTx $(200 \mathrm{U} / \mathrm{ml})$ for the indicated time. The amount of PKA substrate motif phosphorylation in the cells was determined as described in (B). Band intensities of the whole lane from 4 independent experiments were quantified densitometrically and illustrated as means \pm SD $(n=4)$. (E) Effect of SCH 58261 on CTx-induced [cAMP] $]_{\mathrm{i}}$. Serum-starved cells were pre-incubated with SCH $58261(100 \mathrm{nM}$ ) or vehicle for $15 \mathrm{~min}$, followed by stimulation with CTx (200 U/ $\mathrm{ml}$ ) for the indicated time. The amount of intracellular cAMP was determined as described in (A) $(\mathrm{n}=4)$. (F) Effect of SCH 58261 on CTx-induced PKA substrate motif phosphorylation. Serum-starved cells were preincubated with SCH 58261 (100 nM) or vehicle for 15 min, followed by stimulation with CTx (200 U/ml) for the indicated time. The amount of PKA substrate motif phosphorylation in the cells was determined as described in (B) ( $\mathrm{n}=7$ ). (G) Real-time detection of [cAMP $]_{\mathrm{i}}$ by FRET in PC12 cells expressing ${ }^{\mathrm{T}}$ Epac $^{\mathrm{VV}}$. Following recording of a baseline with $(n=3)$ or without $(n=3)$ ADA, the cells were stimulated with CTx $(200 \mathrm{U} / \mathrm{ml})$. Values represent means \pm SD. Asterisks in the panels A indicate significant differences between the curves at those time points (A, C, E, G) or different conditions (D, lower panel). ${ }^{*} \mathrm{P}<0.05$; ${ }^{* *} \mathrm{P}<0.01 ;{ }^{* * *} \mathrm{P}<0.001$. Relevant comparisons between lanes are highlighted by the red frames.

was monitored using an Epac-FRET sensor which was transfected into PC12 cells and allows ratiometric imaging of cyan (CFP) and yellow fluorescent proteins (YFP) fluorescence [21]. Stimulation of FRET sensor-expressing cells with adenosine resulted in an increase in the FRET signal which was blunted in the presence of SCH $58261(1 \mu \mathrm{M})$ or ADA (see online suppl. material, Fig. S1F). Incubation of the cells with CTx induced an increase in the FRET signal after approximately 17 min that remained elevated during the time of measurement of one hour (Fig. 1G), similar to the effect measured by the conventional cAMP enzyme immunoassay. In the presence of ADA the FRET signal signifying [cAMP $]_{i}$ was clearly reduced (Fig. 1G). Together, these data show that extracellular adenosine and $A_{2 A}$ Rs are involved in the CTx-induced increase in $[\mathrm{cAMP}]_{\mathrm{i}}$ and in the activation of adenylyl cyclase/PKA.

In PC3 prostate carcinoma cells, in which $A_{2 B}$ adenosine receptors $\left(A_{2 B} R s\right)$ predominate [25], the $A_{2 B} R$ inhibitor MRS 1754 (see online suppl. material, Fig. S1A) completely inhibited adenosine $(100 \mu \mathrm{M})$-induced PKA substrate motif phosphorylation (Fig. 2A), whereas the 
Fig. 2. AMP also stimulates $A_{2} R s$, and $A_{2 B} R$ antagonist and ADA inhibit GsPCR- or CTx-induced increase in PKA substrate motif phosphorylation in PC3 cells. (A) Effects of ADA and MRS 1754 on adenosine- and AMP-induced PKA substrate motif phosphorylation in PC3 cells. PC3 cells were pre-incubated with ADA (1 U/ml), MRS $1754(10 \mu \mathrm{M})$ or vehicle followed by stimulation with adenosine $(100 \mu \mathrm{M})$, AMP $(100 \mu \mathrm{M})$ or PBS for $10 \mathrm{~min}(\mathrm{n}=3)$. (B) Effect of ADA and SCH 58261 on adenosineand AMP-induced PKA substrate motif phosphorylation in PC3 cells. PC3 cells were pre-incubated with ADA (1 U/ml) or SCH 58261 (100 nM), followed by stimulation with adenosine $(100 \mu \mathrm{M})$, AMP $(100 \mu \mathrm{M})$ or vehicle for $10 \mathrm{~min}$ $(n=3)$. (C) Effect of ADA or the $A_{2 B} R$ in-
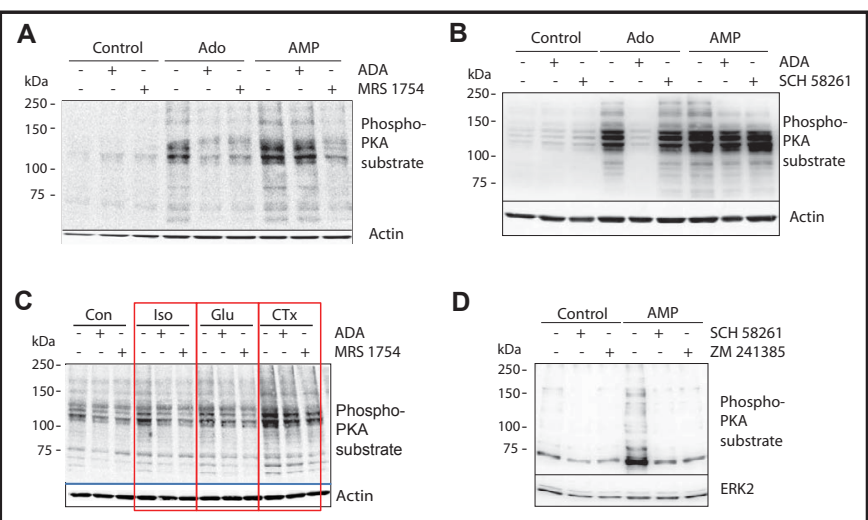

D

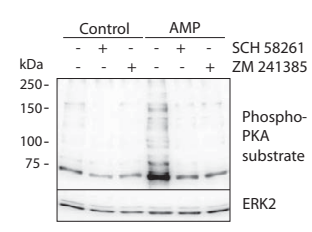

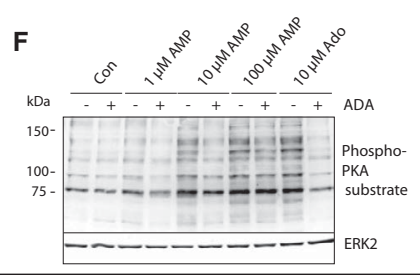

hibitor MRS 1754 on isoproterenol-,

glucagon- or CTx-induced PKA substrate motif phosphorylation in PC3 cells. PC3 cells were pre-incubated with ADA (1 U/ml), MRS $1754(10 \mu \mathrm{M})$ or vehicle followed by stimulation with isoproterenol $(10 \mu \mathrm{M}, 10$ $\mathrm{min})$, glucagon $(1 \mu \mathrm{M}, 15 \mathrm{~min})$ or with $\mathrm{CTx}(200 \mathrm{U} / \mathrm{ml})$ for $40 \mathrm{~min}(\mathrm{n}=3)$. (D) AMP-induced PKA substrate motif phosphorylation is potently inhibited by $\mathrm{A}_{2 \mathrm{~A}} \mathrm{R}$ antagonists in PC12 cells. PC12 cells were stimulated with $100 \mu \mathrm{M}$ AMP in the presence or absence of SCH 58261 (100 nM) or ZM $241385(10 \mu \mathrm{M})(\mathrm{n}=3)$. (E) PC3 cells were incubated with ADA or vehicle and the indicated concentration of AMP or adenosine for 15 min $(n=3)$. (A-E) Cellular lysates were analyzed by immunoblotting and antibodies recognizing phosphorylated PKA substrate motif, $\beta$-actin or ERK2. Con, control; Ado, adenosine; Glu, glucagon; Iso, isoproterenol. Relevant comparisons between lanes are highlighted by the red frames.

$\mathrm{A}_{2 \mathrm{~A}} \mathrm{R}$ blocker SCH $58261(100 \mathrm{nM})$ had no effect (Fig. 2B). MRS $1754(10 \mu \mathrm{M})$ also inhibited the responses to the $\beta$-adrenergic receptor agonist isoproterenol $(10 \mu \mathrm{M})$, to glucagon $(1 \mu \mathrm{M})$ and to CTx in these cells (Fig. 2C). Moreover, ADA reduced the effect of the GsPCR agonists and of CTx on PKA substrate motif phosphorylation in PC3 cells (Fig. 2C). Thus, in PC3 cells, $A_{2 B}$ Rs rather than the $A_{2 A}$ Rs appeared to be involved in activation of adenylyl cyclase by GsPCRs or CTx.

We reasoned that the smaller inhibitory effect of ADA on GSPCR- and CTx-induced PKA substrate motif phosphorylation as compared to the effect of $A_{2} R$ antagonists might be due to the additional involvement of extracellular AMP. AMP is not deaminated by ADA, but it can stimulate adenosine receptors upon its hydrolysis to adenosine. It has also been suggested that AMP stimulates adenosine receptors directly [26, 27]. In this case, AMP $(100 \mu \mathrm{M})$ should elicit an increase in PKA substrate motif phosphorylation that is not or only partially inhibited by ADA, whereas $\mathrm{A}_{2} \mathrm{R}$ antagonists should completely inhibit the AMP response. This was indeed observed in both PC3 (Fig. 2A) and PC12 cells (Fig. 2D and 2E). Remarkably, the inhibitory effect of ADA on AMP-induced PKA substrate motif phosphorylation was more pronounced at low as compared to high AMP concentrations (Fig. 2E). These data suggest that extracellular AMP might be a signaling intermediate in GsPCR- and CTx-induced adenylyl cyclase activation.

CTx elicits an increase in the levels of extracellular adenosine, whereas the levels of extracellular ATP declined

Under basal conditions as well as under conditions of cell stress, the levels of extracellular adenosine are mainly determined by the release of cellular ATP and its subsequent hydrolysis 
Fig. 3. CTx induces an increase in the levels of extracellular adenosine, while decreasing extracellular ATP levels. PC12 were incubated with CTx $(200 \mathrm{U} / \mathrm{ml})$ for the indicated time in serum-free DMEM, followed by determination of the medium levels of adenosine (A), ATP (B) and cAMP (B). Adenosine levels were determined by LC-MS,

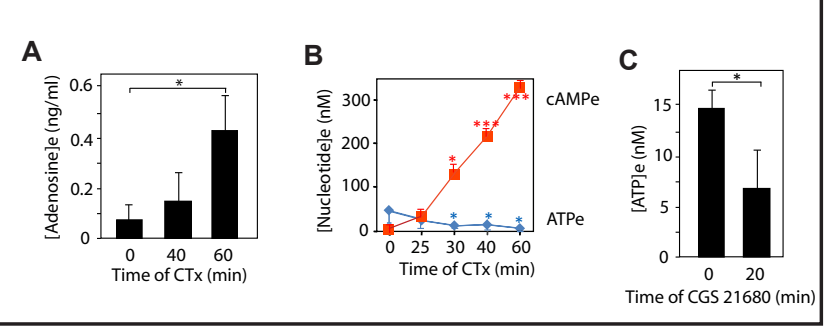
cAMP by enzyme immuno assay and ATP by luciferase assay (B). (C) PC12 cells were incubated for 0 or 20 min with CGS 21680 (10 nM), followed by determination of extracellular ATP levels by the luciferase assay. The values represent means \pm SD of 3-5 independent experiments (A: $n=3 ; B: n=3 ; C: n=3)$. Asterisks represent significant $\left({ }^{*} \mathrm{P}<0.05,{ }^{* * *} \mathrm{P}<0.001\right)$ differences between the indicated conditions $(A, C)$ or as compared to the initial value (B).

Fig. 4. eNPP2 hydrolyzes cAMP and is involved in activation of adenylyl cyclase by CTx in PC12 cells. (A) Recombinant eNPP2 hydrolyzes cAMP. Human recombinant eNPP2 was incubated with $1 \mathrm{mM} \varepsilon$-cAMP in the presence and absence of $\mathrm{S} 32826$ $(100 \mu \mathrm{M})$. The medium was analyzed for $\varepsilon$-AMP by HPLC. Asterisks indicate a significant difference between the two curves at those time points ( $\left.{ }^{* *} \mathrm{P}<0.01 ; \mathrm{n}=3\right)$. (B) Effect of the eNPP2 inhibitor S32826 on CTx on PKA substrate motif phosphorylation in PC12 cells. PC12 cells were incubated with CTx $(200 \mathrm{U} / \mathrm{ml}, 30$ min) in the presence and absence of different concentrations of S32826 with CTx, followed by analysis of the cell lysates by immunoblotting with anti-phosphorylated PKA substrate motif and anti- $\beta$-actin $(n=4)$. (C)
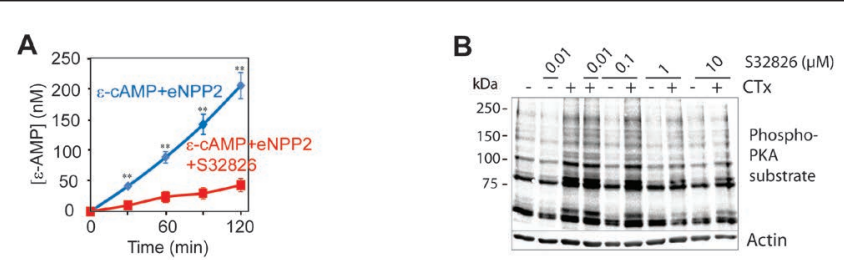

C
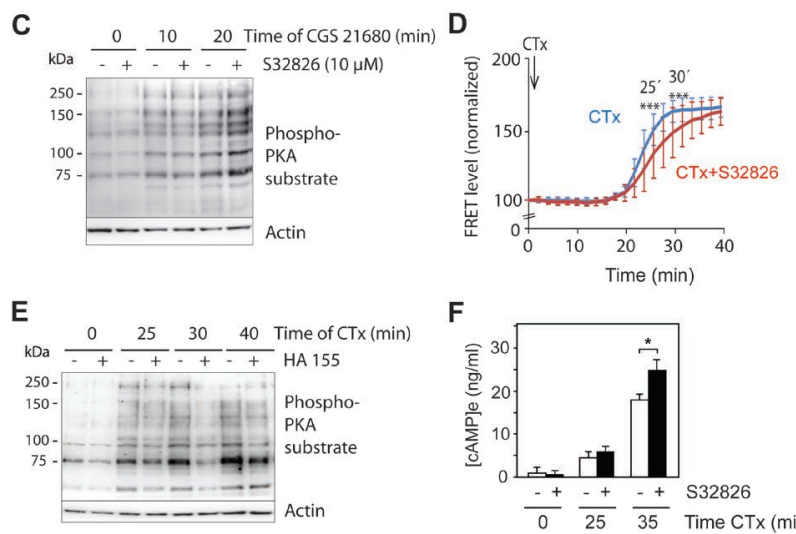

F

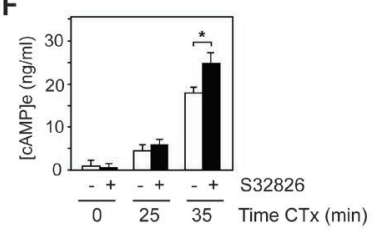

S32826 did not affect CGS 21680-induced PKA substrate motif phosphorylation. PC12 cells were stimulated with $100 \mathrm{nM}$ CGS 21680 in the presence or absence of S32826 (10 $\mu \mathrm{M})$. Cellular lysates were analyzed by immunoblotting and antibodies recognizing phosphorylated PKA substrate motif or $\beta$-actin ( $n=3$ ). (D) FRET traces obtained from PC12 cells expressing ${ }^{\mathrm{T}} \mathrm{Epac}^{\mathrm{VV}}$ with or without S32826. Following recording of a baseline with $(\mathrm{n}=16)$ or without $(\mathrm{n}=17) \mathrm{S} 32826(20 \mu \mathrm{M})$, the cells were stimulated wit CTx $(200 \mathrm{U} / \mathrm{ml})$. Values represent means \pm SD. Asterisks indicate a significant difference between the two curves at those time points $\left({ }^{* * *} \mathrm{P}<0.001\right)$. (E) Effect of HA 155 on CTx-induced PKA substrate motif phosphorylation. PC12 cells were stimulated with CTx in the presence or absence of HA $155(10 \mu \mathrm{M})$ for the indicated time. Subsequently, cell lysates were analyzed by immunoblotting with anti-phosphorylated PKA substrate motif and anti- $\beta$-actin (n=3). (F) S32826 augmented CTx-induced cAMP accumulation in PC12 cells supernatant. PC12 cells were incubated with or without S32826 $(1 \mu \mathrm{M})$ and CTx $(200 \mathrm{U} / \mathrm{ml})$ for the indicated time. The concentration of cAMP in the extracellular medium was determined by enzyme immuno assay. Values represent means \pm SE of 3 independent experiments. The asterisk signifies a significant $(* \mathrm{P}<0.05)$ difference.

to AMP and adenosine by ectonucleoside triphosphate diphosphohydrolases (such as CD39) and CD73, respectively $[12,13,28]$. To investigate if alterations in the extracellular levels of adenosine and its precursors could explain the observed role of $A_{2 A} R$ in CTx-induced adenylyl 


\section{Cellular Physiology Cell Physiol Biochem 2018;45:2516-2528 \\ and Biochemistry Published online: March 19, $2018 \quad$\begin{tabular}{l|l} 
DOI: 10.1159/000488270 2018 The Author(s). Published by S. Karger AG, Basel \\
www.karger.com/cpb
\end{tabular} \\ Pleli et al.: Adenosine Receptors in Adenylyl Cyclase Signaling}

cyclase activation, we examined the impact of CTx on the concentrations of extracellular ATP and adenosine in PC12 cells. CTx caused an increase in the extracellular adenosine levels in these cells (Fig. 3A). Surprisingly, the levels of extracellular ATP declined upon incubation of the cells with CTx (Fig. 3B) or CGS 21680 (10 nM) (Fig. 3C).

We did not detect an increased hydrolysis of exogenous ATP in the presence of CTx, indicating that the CTx-induced decline of the extracellular ATP levels was not due to an increase in ATP hydrolysis (data not shown). Moreover, inhibition of CD39 by ARL67156 (80 $\mu \mathrm{M})$ did not affect the inhibitory effect of SCH $58261(1 \mu \mathrm{M})$ on CTx-induced PKA substrate motif phosphorylation nor did it inhibit CTx-induced PKA substrate motif phosphorylation itself (see online suppl. material, Fig. S2). These findings argue against a role of extracellular ATP in CTx-induced increase in extracellular adenosine concentration and activation of adenosine receptors.

Translocation of adenosine via ENTs represents another source of extracellular adenosine in particular in the brain [14-17]. However, the ENT1 inhibitor NBMPR (500 nM), which inhibits the majority of ENT activity in PC12 cells [17], did not affect CTx-induced PKA substrate motif phosphorylation in these cells (see online suppl. material, Fig. S3).

Ecto-nucleotide phosphodiesterase/pyrophosphatase 2 (eNPP2) can hydrolyze cAMP and is involved in CTX-induced activation of adenylyl cyclase in PC12 cells

Activation of adenylyl cyclase causes not only an increase in $[\mathrm{cAMP}]_{i}$, but also a considerable extrusion of cAMP and a subsequent increase in [cAMP] $]_{e}$ in the majority of cell types [6]. Moreover, hydrolysis of extracellular cAMP has been reported in several cell types [29-34]. Extruded cAMP has been suggested to function as precursor of extracellular adenosine $[7,32]$. Since stimulation of PC12 cells with CTx led to a strong increase in the levels of extracellular cAMP that surpassed those of ATP several-fold (Fig. 3B), we investigated the possibility that extruded cAMP could be the source of extracellular AMP and adenosine upon stimulation of adenylyl cyclase.

eNPP isoenzymes 1-3 are membrane glycoproteins involved in the hydrolysis of extracellular nucleotides and may also hydrolyze cAMP [12]. This has now been explicitly shown for eNPP1 [35]. However, a role of eNPPs in signaling of GsPCR or CTx has not yet been clearly demonstrated. Analysis of the eNPP expression pattern in PC12 cells revealed the presence of eNPP2, for which well-established inhibitors exist, whereas eNPP1 and eNPP3 were absent (see online suppl. material, Fig. S3). This provided the possibility to effectively inhibit potential eNPP-induced extracellular nucleotide hydrolysis activity in these cells using eNPP2 inhibitors. As illustrated in Fig. 4A, eNPP2 indeed hydrolyzed cAMP (1 mM), and this effect was inhibited by S32826 (100 $\mu$ M), an established NPP2 inhibitor. Moreover, S32826 concentration-dependently inhibited CTx-induced PKA substrate motif phosphorylation (Fig.4B), whereas it had no effect on the response to the $A_{2 A} R$ agonist CGS $21680(100 \mathrm{nM})$ (Fig. 4C). S32826 $(10 \mu \mathrm{M})$ also reduced the CTx-induced increase in [cAMP] ${ }_{\mathrm{i}}$ as revealed by the FRET assay (Fig. 4D). HA155 $(10 \mu \mathrm{M})$, a chemically distinct eNPP2 inhibitor, reduced the CTx-induced PKA substrate motif phosphorylation in PC12 cells similar to S32826 (Fig. 4E). Interestingly, S32826 augmented the CTx-induced accumulation of extracellular cAMP (Fig. 4F), pointing to a role of eNPP2 in the hydrolysis of extracellular cAMP in PC12 cells. Together, these data suggest that eNPP2 is involved in CTx-induced adenylyl cyclase activation upstream of $\mathrm{A}_{2 \mathrm{~A}}$ Rs in PC12 cells.

eNPP2/autotaxin is a secreted lysophospholipase D which is well known to catalyze the production of the bioactive lysophosphatidic acid (LPA) from lysophosphaditylcholine [3638]. The majority of LPA receptor subtypes inhibit adenylyl cyclase activity, but some LPA receptors can also activate it [39]. To investigate whether eNPP2 could be involved in CTxinduced adenylyl cyclase activation, we examined the effect of LPA $(1 \mu \mathrm{M})$ on CTx-induced PKA activation. LPA did not increase CTx-induced PKA substrate motif phosphorylation (see online suppl. material, Fig. S5), arguing against a role of LPA in CTx-induced activation of adenylyl cyclase signaling. 


\section{Cellular Physiology Cell Physiol Biochem 2018;45:2516-2528 and Biochemistry Published online: March 19, $2018 \quad \begin{aligned} & \text { DOI: 10.1159/000488270 } 2018 \text { The Author(s). Published by S. Karger AG, Basel } \\ & \text { www.karger.com/cpb }\end{aligned}$ Pleli et al:: Adenosine Receptors in Adenylyl Cyclase Signaling}

Suppression of MRP4 inhibits CTx-induced activation of adenylyl cyclase

Multidrug resistance protein 4 (MRP4) is the major cAMP efflux transporter [8]. To investigate the role of MRP4 in CTx-induced activation of adenylyl cyclase we studied the effect of small interfering (si) RNA-induced suppression of MRP4 expression on CTx- and adenosine-induced PKA substrate motif phosphorylation in PC12 cells. MRP4 knockdown was verified by immunoblotting (see online suppl. material, Fig. S6A). As expected, the siRNA directed against MRP4 reduced the release of cAMP in response to CGS $21680(1 \mu \mathrm{M})$ or CTx from the cells (see online suppl. material, Fig. S6B). Moreover, adenosine elicited a larger increase in PKA substrate motif phosphorylation in MRP4-siRNA-treated cells than in control siRNA-treated cells (Fig. 5). This is in agreement with an increased accumulation of intracellular cAMP and activation of PKA upon activation of adenylyl cyclase when cAMP efflux is inhibited [7]. Despite the increased accumulation of intracellular cAMP upon MRP4 inhibition, CTx elicited a smaller increase in PKA substrate motif phosphorylation in MRP4-deprived cells (Fig. 5), suggesting a role of cAMP efflux through MRP4 in CTx-induced adenylyl cyclase activation.

\section{Discussion}

Signaling via GsPCRs, subsequent activation of adenylyl cyclase and the increase in $[\mathrm{cAMP}]_{i}$ are known to involve the intracellular cAMP effectors PKA, Epacs and cAMP-gated ion channels [2-4]. Here we show that cell surface $G_{s}$ protein-coupled adenosine receptors are a distal target of the signaling pathway following adenylyl cyclase activation. We found that activation of adenylyl cyclase causes a remarkable activation of $A_{2 A} R$ (in PC12 cells) or $A_{2 B} R$ (in PC3 cells). Our data further suggest that the source of extracellular adenosine receptor ligands generated upon activation of adenylyl cyclase might be extruded cAMP rather than extracellular ATP or ADP. Thus, the observed effects of GsPCR and [cAMP], on adenosine receptor activation appear to differ from those occurring under conditions of stress or activation by certain GPCRs which couple to an increase in intracellular calcium, whereby released ATP and ADP activate P2 receptors and - following their hydrolysis by CD39 and CD73 - P1 adenosine receptors [11, $28,40,41]$, or from an increase in extracellular adenosine concentration by translocation of intracellular adenosine via ENTs [14-17].

The concept that stimulation of GsPCR and adenylyl cyclase may modulate adenosine receptor activity has been raised previously [7, 32], mainly based on the observations 1) that the activation of adenylyl cyclase causes not only an increase of [CAMP] $]_{i}$, but also an extrusion of cellular cAMP [6], 2) that some cells and tissues can hydrolyze exogenous cAMP $[32], 3)$ that GsPCR activation can elicit an increase in the levels of extracellular AMP and adenosine in embryonic rat cerebral cortex in dissociated cell culture [29, 30]. Moreover, high concentrations of exogenous cAMP may activate adenosine receptor signaling [e. g. $33,34,42,43]$. Recently, glucagon-induced regulation of hepatic lipid metabolism has been reported to involve the extrusion of cAMP [44]. Thus, an extracellular signaling pathway 


\section{Cellular Physiology Cell Physiol Biochem 2018;45:2516-2528

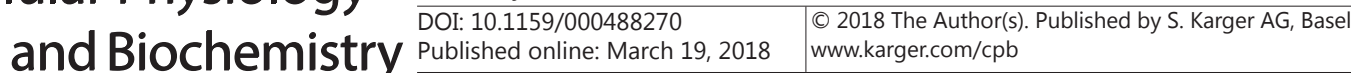 \\ Pleli et al.: Adenosine Receptors in Adenylyl Cyclase Signaling}

termed extracellular cAMP-adenosine pathway has been postulated that encompasses the conversion of extruded cAMP to adenosine and activation of adenosine receptors analogous to the established pathway of extracellular adenosine formation from released ATP occurring under stress conditions [7, 32]. However, a direct involvement of adenosine receptors in signaling via $[\mathrm{CAMP}]_{\mathrm{i}}$ had not clearly been demonstrated. The present study provides several lines of evidence that the activation of adenylyl cyclase by non-adenosine GsPCRs or by CTx is mediated by stimulation of $G_{s}$ protein-coupled adenosine receptors: first, $A_{2 A} R$ antagonists or scavenging of extracellular adenosine by ADA reduced the activation of adenylyl cyclase by non-adenosine GsPCRs and CTx in PC12 cells; second, $\mathrm{A}_{2 \mathrm{~B}} \mathrm{R}$ antagonists or ADA reduced activation of adenylyl cyclase by non-adenosine GsPCRs and CTx in PC3 cells; third, CTx induced the accumulation of extracellular cAMP and adenosine.

The effect of ADA on CTx- and AMP-stimulated adenylyl cyclase activation was smaller than the effect of $\mathrm{A}_{2}$ receptor antagonists, which would be compatible with a role of AMP as a signaling intermediate in CTx-induced adenylyl cyclase activation. Our data further indicate that extracellular ATP, which is the precursor of extracellular adenosine under resting and stress conditions [13], may not be the precursor of extracellular adenosine upon activation of adenylyl cyclase. We found that CTx led to a substantial decline of extracellular ATP levels, which was not due to increased hydrolysis of ATP. Indeed, it has been found that exogenous ATP inhibits activation of adenylyl cyclase in PC12 cells [45]. We instead favor the hypothesis that extruded cAMP rather than extracellular ATP is involved in activation of adenylyl cyclase by GsPCR and CTx in PC12 and PC3 cells. Inhibition of the main cAMP efflux transporter MRP4 reduced CTx-induced PKA substrate motif phosphorylation, suggesting a role of cAMP extrusion in CTx-induced activation of adenylyl cyclase. Inhibition of eNPP2, which we identify here as cAMP-hydrolyzing enzyme, reduced activation of adenylyl cyclase by CTx and increased CTx-induced extracellular cAMP accumulation in PC12 cells. The rate of hydrolysis of cAMP by eNPP2 was relatively low. However, the concentrations of cAMP at the cell surface are probably much higher than in the bulk medium. Moreover, structural interactions of extracellular nucleotide metabolizing enzymes and receptors at the cell surface may facilitate extracellular nucleotide signaling. Thus, eNPP2 interacts with cell surface integrins and thereby promotes localized LPA signaling [46], and $A_{2 A} R$ form complexes with CD73 [47]. Nevertheless, it is currently unknown whether similar structural interactions exist at the cell surface to promote activation of adenosine receptors by secreted cAMP.

Recently, also eNPP1 has been shown to hydrolyze cAMP [35]. Thus, it is possible that different members of eNPP1-3 can be involved in hydrolyzing extracellular cAMP in different cells and tissues. In a mouse model of cardiac pressure overload exogenous cAMP has been shown to reduce cardiac hypertrophy and fibrosis, which was prevented by an eNPP1 inhibitor and adenosine receptor antagonists [43]. Thus, following its hydrolysis by eNPP1, extracellular cAMP might exert its cardioprotective effect via a mechanism similar to that observed in our study. However, whereas PC12 cells were found to express only eNPP2, coexpression of different eNPP1-3 isoenzymes is likely to severely aggravate the elucidation of this pathway in other cell types.

A recent study indicates that inhibition of cholinergic neurotransmission by $\beta_{3}$ adrenoceptors results from adenosine release via equilibrative nucleoside transporters and prejunctional A1 adenosine receptor stimulation in human and rat urinary bladder [17]. In the present study ENT1 inhibition by NBMPR did not influence CTx-induced activation of adenylyl cyclase in PC12 cells, suggesting that this mechanism might not be involved in $A_{2 A} R$ by CTx or GsPCR in these cells. Adenosine release via ENT nevertheless represents an additional mechanism by which GsPCR activation may also increase the extracellular adenosine concentration, in particular in the brain, where extracellular cAMP might be a minor source of extracellular adenosine [48].

eNPP2/autotaxin is a secreted lysophospholipase $\mathrm{D}$, which catalyzes the production of bioactive LPA from lysophosphaditylcholine [36-38]. The eNPP2-LPA axis is responsible for the formation of the vast majority of LPA and thereby plays a key role in cell mobility, 
survival and proliferation [49]. Knockout of mouse eNPP2 results in embryonic lethality due to vascular defects $[50,51]$. The present study provides evidence for a novel role of eNPP2/ autotaxin as a cAMP-hydrolyzing ecto-phosphodiesterase in the signaling via GsPCRs and $[\mathrm{cAMP}]_{\mathrm{i}}$. It may produce extracellular AMP, which in turn leads to activation of adenosine receptors. The role of eNPP2 in adenylyl cyclase signaling appears to be LPA-independent as LPA did not increase CTx-induced PKA substrate motif phosphorylation.

In summary, this study shows that activation of adenylyl cyclase causes P1 purinergic receptor activation by increasing the extracellular concentration of adenosine. In PC12 cells this is mediated by the hydrolysis of extruded cAMP via eNPP2/autotaxin. Adenosine receptors are ubiquitously expressed and exert diverse functions in normal physiology and under pathological conditions such as sepsis, immune regulation, or inflammation $[4,13$, $28,52]$. All these patho/physiological conditions are also regulated by mediators acting through elevation of [cAMP $]_{i^{*}}$ Therefore, it is likely that the discovery in the present study of the modulation of P1 purinergic receptor signaling by [cAMP $]_{i}$ will open new avenues for elucidating the modulatory mechanisms how $[\mathrm{cAMP}]_{\mathrm{i}}$ exerts its diverse regulatory functions within cells.

\section{Acknowledgements}

We thank A. Pexa and A. Deussen (University of Dresden, Germany) for advice and initial HPLC analyses. We thank Kees Jalink (Netherlands Cancer Institute, Amsterdam, The Netherlands) for the ${ }^{\mathrm{T}} \mathrm{Epac}{ }^{\mathrm{VV}} \mathrm{cAMP}$ sensor. This work was supported by grants from the Deutsche Forschungsgemeinschaft (Pi 258/7-4) (A.P.) and the Paul und Ursula Klein Stiftung (T. P.) and LOEWE-Zentrum für Translationale Medizin und Pharmakologie TMP (N.F., D.T., G.G.).

Author contributions

T.P., A.P. and O.W. designed the research and planned the experiments, supported by H.Z. and R.M.B.; T.P., A.P., A.M., D.T., R.M.B., D.M.H, K.D, G.G. and S.Z. analyzed data. T.P., A.P., A.M. and K.D. performed cell treatments and immunoblots, T.P. and A.P. performed the cAMP and ATP assays. T.P. performed the experiments with the siRNAs and RT-PCRs; T.P. and D.M.H. planned and performed the FRET assay; HPLC analyses were planned and performed by T.P. and A.M.; LC-MS/MS analyses were planned by T.P. and performed by D.T. and N.F. A.P. wrote the manuscript, with important contribution of T.P. and H.Z.

\section{Disclosure Statement}

No conflict of interests exists.

\section{References}

1 Kandel ER: The molecular biology of memory storage: A dialogue between genes and synapses. Science 2001;294:1030-1038.

2 Beavo JA, Brunton LL: Cyclic nucleotide research - still expanding after half a century. Nat Rev Mol Cell Biol 2001;3:710-718.

-3 Gancedo JM: Biological roles of cAMP: variations on a theme in the different kingdoms of life. Bio Rev Camb Philos Soc 2013;88:645-668.

4 Bos JL: Epac proteins: multi-purpose cAMP targets. Trends Biochem Sci 2006;31:680-686.

5 Esseltine JL, Scott JD: AKAP signaling complexes: pointing towards the next generation of therapeutic targets? Trends Pharmacol Sci 2013;34:648-655.

6 Davoren PR, Sutherland EW: The effect of L-epinephrine and other agents on the synthesis and release of 


\section{Cellular Physiology Cell Physiol Biochem 2018;45:2516-2528 \begin{tabular}{l|l|l|l|}
\hline DOI: 10.1159/000488270 & (c) 2018 The Author(s). Published by S. Karger AG, Basel
\end{tabular} and BiOchemistry Published online: March 19, 2018 www.karger.com/cpb}

Pleli et al.: Adenosine Receptors in Adenylyl Cyclase Signaling

adenosine 3',5'-phosphate by whole pigeon erythrocytes. J Biol Chem 1963;23:3009-3015.

7 Hofer AM, Lefkimmiatis K: Extracellular calcium and cAMP: second messengers as "third messengers"? Physiology (Bethesda) 2007;22:320-327.

-8 Sager G, Ravna AW: Cellular efflux of cAMP and cGMP - a question about selectivity. Mini Rev Med Chem 2009;9:1009-1013.

-9 Hara Y, Sassi Y, Guibert C, Gambaryan N, Dorfmüller P, Eddahibi S, Lompré AM, Humbert M, Hulot JS: Inhibition of MRP4 prevents and reverses pulmonary hypertension in mice. J Clin Invest 2011;121:28882897.

10 Ralevic V, Burnstock G: Receptors for Purines and Pyrimidines. Pharmacol Rev 1998;50:415-492.

-11 Yegutkin GG: Nucleotide- and nucleoside-converting ectoenzymes: Important modulators of purinergic signalling cascade. Biochim Biophys Acta 2008;1783:673-694.

12 Zimmermann H, Zebisch M, Sträter N: Cellular function and molecular structure of ecto-nucleotidases. Purinergic Signal 2012;8:437-502.

-13 Eltzschig HK, Carmeliet P: Hypoxia and inflammation. N Engl J Med 2011;364:659-665.

14 Meghji P, Tuttle JB, Rubio R: Adenosine formation and release by embryonic chick neurons and glia in cell culture. J Neurochem 1989;53:1852-1860.

15 Mitchell JB, Lupica CR, Dunwiddie TV: Activity-dependent release of endogenous adenosine modulates synaptic responses in the rat hippocampus. J Neurosci 1993;13:3439-3447.

16 Wall MJ, Dale N: Neuronal transporter and astrocytic ATP exocytosis underlie activity-dependent adenosine release in the hippocampus. J Physiol 2013;591:3853-3871.

-17 Silva I, Costa AF, Moreira S, Ferreirinha F, Magalhães-Cardoso MT, Calejo I, Silva-Ramos M, Correia-de-Sá: Inhibition of cholinergic neurotransmission by $\beta_{3}$-adrenoceptors depends on adenosine release and $\mathrm{A}_{1}$ receptor activation in human and rat urinary bladders. Am J Physiol Renal Physiol 2017;313:F388-F403.

18 Waidmann O, Pleli T, Dvorak, K, Baehr C, Mondorf U, Plotz G, Biondi RM, Zeuzem S, Piiper A: Inhibition of the equilibrative nucleoside transporter 1 and activation of $\mathrm{A}_{2 \mathrm{~A}}$ adenosine receptors by $\mathrm{C}^{8}$-modified cAMP analogs and their hydrolytic products. J Biol Chem 2009;284:32256-32263.

19 Piiper A, Elez R, You SJ, Kronenberger B, Loitsch S, Roche S, Zeuzem S: Cholecystokinin stimulates extracellular signal-regulated kinase through activation of the EGF receptor, Yes and protein kinase C: Signal amplification at the level of Raf by activation of protein kinase CE. J Biol Chem 2003;278:7065-7072.

20 Vollmayer P, Koch M, Braun N, Heine P, Servos J, Israr E, Kegel B, Zimmermann H: Multiple ectonucleotidases in PC12 cells: identification and cellular distribution after heterologous expression. J Neurochem 2001;78:1019-1028.

-21 Klarenbeek JB, Goedhart J, Hink MA, Gadella TW, Jalink KA: mTurquoise-based cAMP sensor for both FLIM and ratiometric read-out has improved dynamic range. PLoS ONE 2011;6, e19170.

$\checkmark 22$ Haink G, Deussen A: Liquid chromatography method for the analysis of adenosine compounds. J Chromatogr B Analyt Technol Biomed Life Sci 2003;784:189-193.

-23 Thomas D, Herold N, Keppler OT, Geisslinger G, Ferreirós, N: Quantitation of endogenous nucleoside triphosphates and nucleosides in human cells by liquid chromatography tandem mass spectrometry. Anal Bioanal Chem 2015;407:3693-3704.

-24 Arslan G, Kull B, Fredholm BB: Signalling via A2A adenosine receptor in four PC12 cell clones. Naunyn Schmiedebergs Arch Pharmacol 1999;359:28-32.

-25 Wei Q Costanzi S, Balasubramanian R, Gao ZG, Jacobson KA: A2B adenosine receptor blockade inhibits growth of prostate cancer cells. Purinergic Signal 2013;9:271-280.

-26 Wu SN, Lin YT, Chen SS: Evidence of direct activation of adenosine A1 receptor by 5'-adenosine monophosphate in isolated guinea pig atrial myocytes. Jpn J Physiol 1992;42:35-47.

27 Gao N, Hu HZ, Liu S, Gao C, Xia Y, Wood JD: Stimulation of adenosine A1 and A2A receptors by AMP in the submucosal plexus of guinea pig small intestine. Am J Physiol Gastrointest Liver Physiol 2007;292:G492G500.

28 Junger WG: Immune cell regulation by autocrine purinergic signalling. Nat Rev Immunol 2011;11:201-212.

29 Rosenberg PA, Dichter MA: Extracellular cAMP accumulation and degradation in rat cerebral cortex in dissociated cell culture. J Neurosci 1989;9:2654-2663.

-30 Rosenberg PA, Knowles R, Knowles KP, Li Y: $\beta$-Adrenergic receptor-mediated regulation of extracellular adenosine in cerebral cortex in culture. J Neurosci 1994;14:2953-2965. 


\section{Cellular Physiology Cell Physiol Biochem 2018;45:2516-2528 \begin{tabular}{l|l} 
and Biochemistry Published 10.1159/000488270 & $\begin{array}{l}\text { C) 2018 The Author(s). Published by S. Karger AG, Basel } \\
\text { www.karger.com/cpb }\end{array}$
\end{tabular}}

Pleli et al.: Adenosine Receptors in Adenylyl Cyclase Signaling

-31 Dubey RK, Mi Z, Gillespie DG, Jackson EK: Cyclic AMP-adenosine pathway inhibits vascular smooth muscle cell growth. Hypertension 1996;28:765-771.

32 Jackson EK, Raghvendra DK: The extracellular cyclic AMP-adenosine pathway in renal physiology. Annu Rev Physiol 2004;66:571-599.

-33 Chiavegatti T, Costa Jr VL, Araújo MS, Godinho RO: Skeletal muscle expresses the extracellular cyclic AMPadenosine pathway. Br J Pharmacol 2008;153:1331-1340.

-34 Giron MC, Bin A, Brun P, Etteri S, Bolego C, Florio C, Gaion RM: Cyclic AMP in rat ileum: evidence for the presence of an extracellular cyclic AMP-adenosine pathway. Gastroenterology 2008;134:1116-1126.

-35 Namasivayam V, Lee SY, Müller CE: The promiscuous ectonucleotidase NPP1: molecular insights into substrate binding and hydrolysis. Biochim Biophys Acta 2017;1861:603-614.

36 Stracke ML, Krutzsch HC, Unsworth EJ, Arestad A, Cioce V, Schiffmann E, Liotta LA: Identification, purification, and partial sequence analysis of autotaxin, a novel motility-stimulating protein. J Biol Chem 1992;267:2524-2529.

-37 Umezu-Goto M, Kishi Y, Taira A, Hama K, Dohmae N, Takio K, Yamori T, Mills GB, Inoue K, Aoki J, Arai H: Autotaxin has lysophospholipase D activity leading to tumor cell growth and motility by lysophosphatidic acid production. J Cell Biol 2002;158:227-233.

-38 Tokumura A, Majima E, Kariya Y, Tominaga K, Kogure K, Yasuda K, Fukuzawa K: Identification of human plasma lysophospholipase D, a lysophosphatidic acid producing enzyme, as autotaxin, a multifunctional phosphodiesterase. J Biol Chem 2002:277:39436-39442.

-39 Choi JW, Herr DR, Noguchi K, Yung YC, Lee CW, Mutoh T, Lin ME, Teo ST, Park KE, Mosley AN, Chun J: LPA receptors: subtypes and biological actions. Annu Rev Pharmacol Toxicol 2010;50:157186.

-40 Chen Y, Corriden R, Inoue Y, Yip L, Hashiguch N, Zinkernagel A, Nizet V, Insel PA, Junger WG: ATP release guides neutrophil chemotaxis via P2Y2 and A3 receptors. Science 2006;314:1792-1795.

-41 Eltzschig HK, Eckle T, Mager A, Küper N, Karcher C, Weissmüller T, Boengler K, Schulz R, Robson SC, Colgan CP: ATP release from activated neutrophils occurs via Connexin 43 and modulates adenosine-dependent endothelial cell function. Circ Res 2006;99:1100-1108.

-42 Do T, Sun Q Beuve A, Kuzhikandathil EV: Extracellular cAMP inhibits D1 dopamine receptor expression in CAD catecholaminergic cells via A2a adenosine receptors. J Neurochem 2007;101:619-631.

-43 Sassi Y, Ahles A, Truong DJ, Baqi Y, Lee SY, Husse B, Hulot JS, Foinquinos A, Thum T, Müller CE, Dendorfer A, Laggerbauer B, Engelhardt S: Cardiac myocyte-secreted cAMP exerts paracrine action via adenosine receptor activation. J Clin Invest 2014;124:5385-5397.

-44 Lv S, Qiu X, Li J, Liang J, Li W, Zhang C, Zhang ZN, Luan B: Glucagon-induced extracellular cAMP regulates hepatic lipid metabolism. J Endocrinol 2017;234:73-87.

45 Unterberger U, Moskvina E, Scholze T, Freissmuth M, Boehm S: Inhibition of adenylyl cyclase by neuronal P2Y receptors. Br J Pharmacol 2002;135:673-684.

-46 Hausmann J, Kamtekar S, Christodoulou E, Day JE, Wu T, Fulerson Z, Albers HM, van Meeteren LA, Houben AJ, van Zeij IL, Jansen S, Andries M, Hall T, Pegg LE, Benson TE, Kasiem M, Harlos K, Kooi CW, Smyth SS, Ovaa H, Bollen M, Morris AJ, Moolenaar WH, Perrakis A: Structural basis of substrate discrimination and integrin binding by autotaxin. Nat Struct Mol Biol 2011;18:198-204.

-47 Augusto E' Matos M, Sévigny J, El-Tayeb A, Bynoe MS, Müller CE, Cunha RA, Chen JF. Ecto-5'-nucleotidase (CD73)-mediated formation of adenosine is critical for the striatal adenosine A2A receptor functions. J Neurosci 2013;33:11390-11399.

48 Brundege JM, Dunwiddie TV: Modulation of excitatory synaptic transmission by adenosine released from single hippocampal pyramidal neurons. J Neurosci 1996;16:5603-5612.

-49 van Meeteren LA, Ruurs P, Stortelers C, Bouwman P, van Rooijen MA, Pradère JP, Pettit TR, Wakelam MJ, Saulnier-Blache JS, Mummery CL, Moolenaar WH, Jonkers J: Autotaxin, a secreted lysophospholipase D, is essential for blood vessel formation during development. Mol Cell Biol2006;26:5015-5022.

50 Moolenaar WH, Perrakis A: Insights into autotaxin: how to produce and present a lipid mediator. Nat Rev Mol Cell Biol 2011;12:674-679.

51 Tanaka M, Okudaira S, Kishi Y, Ohkawa R, Iseki S, Ota M, Noji S, Yatomi Y, Aoki J, Arai H: Autotaxin stabilizes blood vessels and is required for embryonic vasculature by producing lysophosphatidic acid. J Biol Chem 2006;281:25822-25830.

52 Idzko M, Ferrari D, Eltzschig HK: Nucleotide signalling during inflammation. Nature 2014;509:310-317. 